\title{
Evaluation of Investment Risk in Thermal Power Project Based on Risk Matrix
}

\author{
Jianna Zhao \\ Department of Economics and Management \\ North China Electric Power University \\ Baoding,Hebei,China \\ zhjnzhf@163.com
}

\author{
Chunchen Wang \\ Department of Economics and Management \\ North China Electric Power University \\ Baoding,Hebei,China \\ 1587100807@qq.com
}

\begin{abstract}
Under the complicated variable international economic environment, investment of thermal power project faces many risks. In order to reduce the risk loss which due to thermal power project investment, the paper uses risk matrix to evaluate factors of investment risk in thermal power project. First, the paper establishes the index system of factors of investment risk in thermal power project, and then has the study and evaluation of investment risk base on risk matrix. Finally, demonstrating the feasibility and practicality of the method is made by example analysis. The paper provides a scientific reasonable effective method on the evaluation of investment risk in thermal power project.
\end{abstract}

Keywords - thermal power project; risk matrix; investment risk; evaluation of risk

\section{INTRODUCTION}

With the rapid development of economy, the power industry is regarded as the forerunner of the economic development and its requirements should be compatible with economic growth. But now, the existing thermal power enterprises still cannot satisfy the demand of economic development. Therefore the investment of the thermal power engineering project is still in the rising period in our country. Along with the rapid development and variation of economy, science and technology, culture, the investment of thermal power project increasingly shows complexity and uncertainty. The thermal power project belongs to capital intensive enterprise, and its investment capital is huge, long cycle and complex technology, and it faces more risks, and its loss caused by risks is bigger also, and its investment risks is increasing. The thermal power project needs to systematically deal with comprehensive risk management, removes the possible risk factors early and does preparedness and mitigation for the inevitable risk.

At present, the risk management of the thermal power project investment is still in a weak link in our country. In order to cultivate a keen sense of smell about the risk awareness, we should to accurately evaluate many risk factors at the early stage of the thermal power project investment. A reasonable evaluation result of investment risk should be as a prerequisite which regards to invest and construct a project smoothly. A comparatively perfect investment risk evaluation study of the thermal power project, can lay a good foundation for the project smoothly. This paper uses the risk matrix the method analyzes the risk factors and assesses the risk method to evaluate risks which are facing in the thermal power project investment. Through the evaluation, we may draw risk level, and the risk level will provide the basis for thermal power project is how to reduce risk loss. At the same time, this method also provides certain reference for the thermal power project investment risk evaluation research.

\section{CONSTRUCTION OF INDEX SYSTEM}

Due to the thermal power project investment risk factors are very complicated. But in order to guarantee the objectivity and effectiveness of the final evaluation results, this paper combines with the characteristics of thermal power engineering project investment risk significantly, draws lessons from the domestic and foreign literature related engineering project investment risk management theory, and consults a number of senior engineers involved in the project construction. Finally this article selects 11 indicators of risk from politics, technology, natural, management four aspects, to build a thermal power project investment risk evaluation index system. As shown in table 1.

TABLE I. THERMAL POWER PROJECT INVESTMENT RISK EVALUATION INDEX SYSTEM

\begin{tabular}{|c|c|c|}
\hline \multirow{5}{*}{$\begin{array}{c}\text { thermal } \\
\text { power } \\
\text { project } \\
\text { investment } \\
\text { risk } \\
\text { evaluation } \\
\text { index } \\
\text { system } \\
\text { A }\end{array}$} & rule layer & index layer \\
\hline & political risk $\mathrm{B}_{1}$ & $\begin{array}{c}\text { National policy risk } \mathrm{C}_{11} \\
\text { legal risk } \mathrm{C}_{12} \\
\text { civil war risk } \mathrm{C}_{13}\end{array}$ \\
\hline & technical risk $B_{2}$ & $\begin{array}{c}\text { design risk } \mathrm{C}_{21} \\
\text { construction risk } \mathrm{C}_{22} \\
\text { technical standard matching risk } \mathrm{C}_{23}\end{array}$ \\
\hline & natural risk $B_{3}$ & $\begin{array}{c}\text { climate risk } C_{31} \\
\text { environmental risk } C_{32} \\
\text { force majeure risks } C_{33}\end{array}$ \\
\hline & management risk $B_{4}$ & $\begin{array}{c}\text { schedule management risk } \mathrm{C}_{41} \\
\text { human resource risk } \mathrm{C}_{42}\end{array}$ \\
\hline
\end{tabular}

III. MODEL OF THE RISK MATRIX METHOD

\section{A. The content of the risk matrix method}

Risk matrix method, which is put forward by the U.S. air force system power center (ESC, Electronic Systems Center) in 1995, is a structured approach about recognizing the importance of the project risk in the process of project management. Through the qualitative and quantitative analysis, probability. 
B. The basic steps of the risk matrix method

1 ) Determine the risk matrix model
According to the risk assessment model, determine the risk matrix of thermal power project investment risk. As shown in table 2 .

TABLE II. THERMAL POWER PROJECT INVESTMENT RISK MATRIX MODEL

\begin{tabular}{|c|c|c|c|c|c|c|}
\hline $\begin{array}{c}\text { risk } \\
\text { factors (R) }\end{array}$ & $\begin{array}{c}\text { risk } \\
\text { Impact } \\
(\mathrm{I})\end{array}$ & $\begin{array}{c}\text { risk } \\
\text { probability } \\
(\mathrm{P})\end{array}$ & $\begin{array}{c}\text { risk } \\
\text { Level } \\
(\mathrm{RR})\end{array}$ & $\begin{array}{c}\text { borad } \\
\text { sequence } \\
\text { value }\end{array}$ & $\begin{array}{c}\text { risk factor } \\
\text { weight } \\
(\mathrm{RW})\end{array}$ & $\begin{array}{c}\text { the } \\
\text { risk } \\
\text { evaluation }\end{array}$ \\
\hline & & & & & & \\
\hline
\end{tabular}

\section{2) The provisions of the risk impact and risk probability}

According to the GB/T 20984-2007 classification regulatory responsibility, risk impact and risk probability are divided into 5 grades. As shown in table 3and4.

TABLE III. LEVEL OF THE RISK IMPACT

\begin{tabular}{|c|c|}
\hline risk impact level & explanation \\
\hline key & the whole project failure \\
\hline serious & $\begin{array}{l}\text { the objectives of the project has a serious } \\
\text { decline }\end{array}$ \\
\hline general & $\begin{array}{l}\text { project goal affected by moderate and part of } \\
\text { the target can be realized }\end{array}$ \\
\hline tiny & $\begin{array}{l}\text { project goal affected by mild and the basic } \\
\text { objectives can be realized }\end{array}$ \\
\hline ignore & project objectives are not affected \\
\hline
\end{tabular}

TABLE IV. THE PROBABILITY OF RISK OCCURRENCE

\begin{tabular}{|c|c|}
\hline the probability of risk occurrence $(\%)$ & explanation \\
\hline $0 \sim 10$ & almost never happen \\
\hline $11 \sim 40$ & rarely occurs \\
\hline $41 \sim 60$ & possible \\
\hline $61 \sim 90$ & most likely to happen \\
\hline $1 \sim 100$ & the general will \\
\hline
\end{tabular}

\section{3) determine the level of risk}

According to the probability of risk events and the consequences of a risk event, the risk can be divided into high risk, medium risk and low risk. As shown in table 5.

TABLE V. THE LEVEL OF RISK

\begin{tabular}{|c|c|c|c|c|c|}
\hline risk level & ignore & tiny & general & serious & key \\
\hline $0 \sim 10$ & low & low & low & medium & medium \\
\hline $11 \sim 40$ & low & low & medium & medium & high \\
\hline $41 \sim 60$ & low & medium & medium & medium & high \\
\hline $\begin{array}{l}61 \sim 90 \\
\end{array}$ & medium & medium & medium & medium & high \\
\hline $91 \sim 100$ & medium & high & high & high & high \\
\hline
\end{tabular}

\section{4) Borad sequence value}

Board sequencing method,which is based on the assessment of the risk possibility and the severity of results, an algorithm to sort the risk with the vote, can achieve the same level of multiple levels of risk ranking to achieve better risk management.The number of Board for risk $i$

$$
b_{i}=\sum\left(N-r_{i k}\right)
$$

In the formula, $i$ is a specific index, $N$ is the total number of risk index, $r_{i k}$ is the risk rating of the risk $i$ under the standard $k, k$ is a standard (When $k=1$, said the risk impact; When $k=2$, said the risk probability).

5) Determine the risk weight

For the weight of each risk factor can be determined by analytic hierarchy process (ahp). The first group of experts give the score for each risk factor, then we construct the judgment matrix and obtain the weight value of each factor by computing. 
6) Determine quantification table of the risk level

TABLE VI. QUANTIFICATION TABLE OF THE RISK LEVEL

\begin{tabular}{|c|c|}
\hline risk level & quantitative score \\
\hline low & 0.2 \\
\hline medium & 0.6 \\
\hline high & 0.8 \\
\hline
\end{tabular}

\section{7) determine the comprehensive risk}

Risk comprehensive evaluation result is equal to each risk factor corresponding to the risk weight multiplied by the number of quantitative risk level

$$
Y=\sum_{i=1}^{N} R_{i} w_{i}
$$

In the formula, $r_{i}$ is the level of risk, $N$ is the number of risk factors, $w_{i}$ is the risk weight.

\section{EVALUATION OF THE RISK MATRIX METHOD IN THE THERMAL POWER PROJECT INVESTMENT RISK}

Set a thermal power project as an example. According to 11 thermal power project investment risk index system which has been selected and the risk matrix method. Combining with the actual management of the thermal power engineering project investment risk, we invited the investment risk experts and the thermal power construction project experts composing experts group to evaluate the thermal power engineering project investment risk factor. And then the risk assessment matrix is obtained. Risk assessment of the final results is shown in table 7.

TABLE VII. THE RISK ASSESSMENT MATRIX

\begin{tabular}{|c|c|c|c|c|c|c|c|}
\hline risk factors & $\begin{array}{l}\text { the serial } \\
\text { number }\end{array}$ & $\begin{array}{c}\text { risk } \\
\text { Impact }\end{array}$ & $\begin{array}{c}\text { risk } \\
\text { probability } \\
(\%)\end{array}$ & $\begin{array}{l}\text { risk level } \\
\quad(R)\end{array}$ & $\begin{array}{c}\text { borad } \\
\text { sequence } \\
\text { value }\end{array}$ & $\begin{array}{l}\text { weight } \\
\text { W }\end{array}$ & $\begin{array}{c}\text { the risk comprehensive } \\
\text { evaluation }\end{array}$ \\
\hline national policy risk & 1 & general & $20 \sim 40$ & medium & 6 & 0.071 & \multirow{11}{*}{0.648} \\
\hline legal risk & 2 & tiny & $20 \sim 40$ & low & 6 & 0.034 & \\
\hline civil war risk & 3 & serious & $0 \sim 10$ & medium & 4 & 0.068 & \\
\hline design risk & 4 & key & $45 \sim 60$ & high & 1 & 0.160 & \\
\hline construction risk & 5 & key & $45 \sim 60$ & high & 1 & 0.148 & \\
\hline $\begin{array}{l}\text { technical standard } \\
\text { matching risk }\end{array}$ & 6 & serious & $20 \sim 40$ & medium & 2 & 0.098 & \\
\hline climate risk & 7 & tiny & $60 \sim 80$ & medium & 7 & 0.051 & \\
\hline environmental risk & 8 & tiny & $60 \sim 70$ & medium & 8 & 0.045 & \\
\hline force majeure risks & 9 & disaster & $0 \sim 10$ & medium & 8 & 0.078 & \\
\hline $\begin{array}{c}\text { schedule management } \\
\text { risk }\end{array}$ & 10 & serious & $40 \sim 60$ & medium & 3 & 0.126 & \\
\hline human resource risk & 11 & general & $40 \sim 70$ & medium & 4 & 0.112 & \\
\hline
\end{tabular}

\section{CONCLUSION}

Because of the uncertainty of the risk itself and according to the actual situation of the thermal power project risk, this paper proposed to evaluate the thermal power project investment risk by risk matrix method.

- Studying on the thermal power project investment risk evaluation is a complex work, with a reasonable results of investment risk evaluation as a prerequisite, a project will be invested and constructed successfully. The construction of thermal power project is a huge systematic projec, risk factors should be selected and analyzed before the investment and construction. In this paper, through four aspects of political, technical, management, nature chooses 11 indexes as the evaluation factors, and the evaluation system is comprehensive and clear.

- The overall risk value which is calculated by using the risk matrix method for thermal power project investment is 0.684 . The evaluation method is simple, and realizes the combination of qualitative and quantitative, comprehensively and intuitively reflect the influence of the risk level by each index.

- The deficiencies of processing more risk structure of using the risk matrix method are overcomed by using risk matrix method and borda order values method comprehensively. And it is more practical at the condition of more risk category and relatively concentrated same risk level. 


\section{REFERENCE}

[1] Min Han.Study on the risk management of thermal power project[D].North China Electric Power University(Baoding),2008.

[2] Xueyi Tong.Study of thermal power project risk management[D].North China Electric Power University(Beijing),2012.

[3] Paul R, Garvey P R, Lansdowne Z F,Risk Matrix; An Approch for Identifying, Assessing, and Ranking Program Risks [J]. Air Force Journal of Logistics, 1998.
[4] Van Newenhizen J. The Borda Method is Most Likely to Respect the Condorcet Principie [J], Economic Theory, 1992.

[5] Xinghua Dang, Zhengchao Huang, Qiaoyan Zhao.The risk assessment of venture investment project based on risk matrix[J].Scientific and Technological Progress and Countermeasures, 2006.

[6] Qichao Zhu, Xinghua Kuang, Yongping Shen. Risk matrix method and review of the application[J].Chinese Engineering Science, 2003. 